\title{
La comunicación de valores en la publicidad durante la primera oleada de covid-19 en España*
}

\author{
Ángel Rodríguez-Bravo \\ David Badajoz \\ Erika Marisol Ruiz Castillo \\ Paulina Guajardo Figueroa \\ Adriana Margarita Hernández-López \\ Universitat Autònoma de Barcelona \\ angel.rodriguez@uab.cat \\ david.badajoz@uab.cat \\ erikamarisol.ruiz@e-campus.uab.cat \\ paulina.guajardo@e-campus.uab.cat \\ adrianamargarita.hernandez@e-campus.uab.cat
}

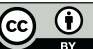

Fecha de presentación: octubre de 2020

Fecha de aceptación: abril de 2021

Fecha de publicación: diciembre de 2021

Cita recomendada: RodríGUEZ-Bravo, Á.; BADAJOZ, D.; RUIZ CASTILLO, E. M.; GUAJARDo FigueroA, P. y HernándeZ-López, A. M. (2021). «La comunicación de valores en la publicidad durante la primera oleada de covid-19 en España». Anàlisi: Quaderns de Comunicació i Cultura, 65, 21-48. DOI: <https://doi.org/10.5565/rev/analisi.3361>

\section{Resumen}

En este artículo se miden los valores comunicados en la oleada publicitaria que se distribuyó durante la primera etapa crítica de la pandemia de covid-19 en Espańa. La investigación se apoya en la recopilación en línea de 45.000 respuestas a 1.880 test por parte de 470 receptores españoles e iberoamericanos. Cada uno de ellos evaluó 25 valores, tras exponerse a una muestra de cinco anuncios emitidos por televisión abierta durante el periodo estudiado. La metodología parte de cuatro objetivos de investigación y se apoya en un nuevo instrumento de medición científica: ProtocoloEva ${ }^{\circledR}$. Las conclusiones revelan una estrategia comunicativa muy similar por parte de las cuatro fuentes estudiadas. Los valores cooperación, bienestar, esfuerzo, familia, salud, respeto y responsabilidad fueron transmitidos de manera intensa y son fuertemente homogéneos en todos los anuncios estudiados; en cambio, los valores derechos, justicia-equidad, dignidad y libertad fueron comunicados con una intensidad mucho más baja y de manera heterogénea. Se produce una transmisión más alta de valores entre las

* También han formado parte activa del equipo de investigación que presenta este artículo: Norminanda Montoya, Luis E. Romero, Diana Miranda, Marillia Oliveira, Silvia A. Cristian Ladaga, Lissa Ferreira y Gerson Martins. 
personas religiosas y entre las latinoamericanas, y una recepción de valores muy débil en las personas que han sufrido el covid-19 directamente o de manera cercana.

Palabras clave: valores; publicidad; pandemia; covid-19; eficacia publicitaria; estudios contextuales

Resum. La comunicació de valors en la publicitat durant la primera onada de covid-19 a España

En aquest article es mesuren valors comunicats en l'onada publicitària que es va distribuir durant la primera etapa crítica de la pandèmia de covid-19 a Espanya. La investigació es basa en la recopilació en línia de 45.000 respostes a 1.880 tests per part de 470 receptors espanyols i iberoamericans. Cadascun va avaluar 25 valors després de ser exposats en una mostra de cinc anuncis emesos per televisió oberta durant el període estudiat. La metodologia parteix de quatre objectius d'investigació i es basa en un nou instrument de mesura científica: ProtocoloEva ${ }^{\oplus}$. Les conclusions revelen una estratègia comunicativa molt similar per part de les quatre fonts estudiades. Els valors cooperació, benestar, esforç, família, salut, respecte i responsabilitat es van transmetre de manera intensa i són fortament homogenis en tots els anuncis estudiats; en canvi, els valors drets, justícia-equitat, dignitat i llibertat van ser comunicats amb una intensitat molt més baixa i de manera heterogènia. Es produeix una transmissió més alta de valors entre les persones religioses i entre les llatinoamericanes, i una recepció de valors molt feble entre les persones que han patit la covid-19 de manera directa o propera.

Paraules clau: valors; publicitat; pandèmia; covid-19; eficàcia publicitària; estudis contextuals

Abstract. Communication of values in advertising during the fifth wave of COVID-19 in Spain

This article measures the values communicated in the wave of advertising launched during the first critical stage of the COVID-19 pandemic in Spain. The research is based on 45,000 on-line responses to 1,880 reception tests by 470 Spanish and Latin American recipients. Each of the receivers evaluated 25 values, after being exposed to a sample of five ads broadcast on TV during the period studied. The methodology is based on four research objectives and is supported by a new scientific measurement instrument: ProtocoloEva $^{\circledR}$. Its conclusions reveal a very similar communication strategy in the four sources studied. The values cooperation, well-being, effort, family, health, respect and responsibility were strongly conveyed, and are strongly homogeneous in all the ads studied. In contrast, the values rights, justice-equity, dignity and freedom were perceived with a much lower intensity, and heterogeneously. There was a higher transmission of values among religious people and Latin American people, and a very weak reception of values in people who have suffered COVID-19 directly or closely.

Keywords: values; advertising; pandemic; COVID-19; advertising effectiveness; contextual studies

\section{Introducción}

El miércoles 11 de marzo de 2020 la OMS comunica la existencia de una pandemia por coronavirus y tres días después el Gobierno español declara el estado de alarma y pone a todo el país en confinamiento (Kamps y Hoff- 
mann, 2020: 18-27). España es considerado uno de los países del mundo más afectados por la pandemia: 245.268 personas contagiadas, 150.376 recuperadas ${ }^{1}$ y 27.136 fallecidas (La Vanguardia, 23 de mayo de 2020).

El mes de marzo de 2020 la audiencia de televisión acumulada ascendió en España a 37 millones, con una cobertura del $95,8 \%$ de la población con más de 18 años, el 82,4\% de la cual navegó por Internet en algún momento, y el consumo audiovisual (televisión + Internet) obtuvo una media diaria de 6 horas y 22 minutos. En abril el consumo de televisión batió un récord histórico: 302 minutos (5,03 h) diarios (Barlovento Comunicación, 2020).

En este contexto se produce una paradoja comunicativa: mientras la crisis económica derivada del confinamiento paraliza la inversión publicitaria, la pandemia parece una buena oportunidad para que las marcas se adapten a la contingencia, creando publicidad con mensajes de unión, solidaridad y esperanza (Beristain, 2020).

Los datos que comparan la ocupación publicitaria de medios en marzo y abril del 2019 con la del 2020 muestran una evolución negativa del -16,65\% en marzo (Arce Media, 2020a) y del $-47,31 \%$ en abril (Arce Media, 2020b). No obstante, en esta investigación se detectó que entre el 1 de marzo y el 30 de abril se emitieron en España 66 anuncios publicitarios nuevos vinculados a la pandemia.

Que una parte relevante de la producción publicitaria abandonara repentinamente sus objetivos centrales habituales para substituirlos por la asociación de la marca a los valores humanos vinculados a la pandemia de la covid19 es, sin duda, una situación tan disruptiva que merecía ser estudiada. Frente al fenómeno que acabamos de describir, surgen preguntas como: ¿qué tendencias generales han aparecido en la oleada publicitaria asociada a la epidemia?, ¿cuáles fueron los valores comunicados?, ¿qué características de los receptores resultaron determinantes?, ¿cómo han utilizado la comunicación de valores las marcas estudiadas?

Para encontrar las repuestas se desarrolló un diseño empírico exploratorio basado en pruebas de recepción: consistió en exponer 470 receptores a una muestra de cinco anuncios publicitarios de las organizaciones que lanzaron mensajes relacionando pandemia y valores, con el objetivo de medir la carga de cualidades percibida por esas personas.

\subsection{Objetivos}

Los objetivos que se persiguen en esta investigación son los siguientes:

1. Identificar las tendencias generales en cuanto a la transmisión de valores en la publicidad.

2. Localizar los valores dominantes percibidos por los sujetos expuestos a los mensajes publicitarios.

1. Dato correspondiente al 18 de mayo de 2020. 
3. Delimitar qué rasgos sociodemográficos de los receptores han sido determinantes para la percepción de los valores.

4. Identificar las estrategias comunicativas asociadas a los valores que han utilizado las marcas estudiadas durante la primera oleada de covid-19 en España.

\section{Marco teórico}

La investigación en torno a los valores humanos ha recorrido un largo trayecto desde que Sheler (1916) revisó los conceptos morales y éticos planteados por Kant (1786) para desarrollar su propuesta de cuatro grandes modalidades: valores hedónicos o sensibles, valores vitales, valores morales y valores religiosos.

Cincuenta años después, Rokeach (1973) localizó un inventario de 36 valores organizado en dos categorías: instrumentales y terminales. Más tarde, Schwartz (1996) revisará este inventario para proponer un modelo que articulaba 57 valores humanos organizados en diez que consideraba básicos: universalismo, benevolencia, conformidad, tradición, seguridad, logro, poder, hedonismo, autodirección y estimulación. Estos dos autores suponen un punto de inflexión en la investigación y abren una nueva etapa en la cual los valores humanos serán aplicados como una herramienta para observar y medir la evolución social.

Los valores humanos emergen como concepto científico de éxito en las últimas décadas, configurándose dos líneas dominantes:

- Una corriente sociocultural (Delfino y Muratori, 2011), apoyada en los trabajos de Rokeach y Schwartz que tiene como objetivo central observar la evolución social a partir de la identificación y la medición de sus valores. El desarrollo de estudios periódicos sistemáticos y generalizados como la World Values Survey ${ }^{2}$ o la European Social Survey ${ }^{3}$, que están utilizándose actualmente como fuentes de datos para la investigación social, son ejemplos de esta línea de trabajo.

- Una corriente sociotécnica (Rodríguez Bravo et al., 2020), que aplica el modelo de Schwartz a la solución de problemas técnicos concretos. En esta línea se han desarrollado investigaciones destinadas a objetivos tan diversos como: localizar nuevos nichos de mercado (Guzmán-Obando et al., 2016); explicar resultados educativos (Giusta, Hashimzade y Myles, 2017); orientar las acciones del consumidor (Salim Saji, 2015; Walls, 2018); explicar el éxito electoral (Hernández Olmedo, 2016; Sepúlveda Ríos, 2017); etc.

Finalmente, el estudio de los valores humanos confluye con la literatura científico-técnica publicitaria en el marco de la responsabilidad social de la

2. <https://www.worldvaluessurvey.org/wvs.jsp>.

3. <https://www.europeansocialsurvey.org/>. 
publicidad o publicidad con causa social. Esta corriente explora las posibilidades de la publicidad como herramienta para contribuir al cambio social (Rodrigo Martín y Rodrigo Martín, 2014).

En tanto que lo que propone este artículo es estudiar la transmisión de valores a través de anuncios publicitarios emitidos en un contexto de crisis sanitaria grave, esta investigación se enmarca en el punto de conexión entre el desarrollo de herramientas para explorar y medir los valores humanos y su aplicación publicitaria.

\section{Metodología}

Este estudio se apoya en el aplicativo en línea denominado ProtocoloEva $a^{\otimes 4}$, que articula un protocolo de testeo, una escala de valoración de la presencia e intensidad de los valores percibidos y un algoritmo para el tratamiento automatizado de los datos obtenidos. Este procedimiento permite medir la carga de valores que cualquier mensaje concreto comunica a un grupo de sujetos determinado. Tanto la escala de medición como el protocolo de testeo y el algoritmo en que se basan los índices numéricos resultantes han sido validados (Rodríguez Bravo et al., 2013, 2017) y aplicados en diversas investigaciones (Mas Manchón et al., 2015, 2016; Lage Fombuena, 2016; Montoya, Rodríguez Bravo y Lopes, 2018, Rodríguez Bravo et al., 2020).

Para alcanzar los objetivos propuestos este estudio centra su atención en la producción publicitaria española, desarrollando la investigación en tres etapas:

1. Selección de una muestra de anuncios publicitarios emitidos por las televisiones españolas durante marzo y abril de 2020.

2. Exposición de la muestra de anuncios a distintos grupos de receptores (test de recepción) mediante la herramienta ProtocoloEva ${ }^{\circledR}$, con objeto de medir los valores percibidos.

3. Análisis e interpretación de los resultados del test.

\subsection{Selección de la muestra de anuncios}

Los criterios que debían cumplir los anuncios publicitarios para ser seleccionados como parte de la muestra fueron los siguientes:

a) Provenir de fuentes institucionales y de fuentes comerciales.

b) Exponer contenidos relacionados con la pandemia de covid-19.

4. ProtocoloEva $a^{\oplus}$ es una herramienta para la medición y evaluación de valores en mensajes audiovisuales desarrollada y validada en el Laboratorio de Análisis Instrumental de la Comunicación (LAICOM, 2017 SGR115) de la Universidad Autónoma de Barcelona y es accesible desde la dirección: <https://a-eva.org/protocolo-eva/>. El desarrollo de esta herramienta fue financiado por el Ministerio de Economía y Competitividad (CSO2012$33170)$. 
c) Haber sido emitidos por televisión ${ }^{5}$ entre el 1 de marzo de 2020 y el 31 de abril de 2020.

La localización de anuncios se realizó explorando los sitios web especializados en marketing de ReasonWhy, Einatec, El Publicista, Puro Marketing, La Publicidad, Marketing Directo y Kantar para localizar toda la propaganda que hubiese sido difundida por televisión durante los meses de marzo y abril de 2020. La muestra extraída fue exhaustiva, puesto que se encontraron 68 piezas que cumplían con los tres criterios preestablecidos.

La fatiga de los sujetos experimentales al usar ProtocoloEva ${ }^{\circledR}$ aparece tras evaluar entre cuatro y ocho anuncios de unos 30 segundos. Se decidió, en consecuencia, limitar a cinco el número de anuncios evaluados en cada test. El criterio seguido para la selección se centró en localizar los que mostraban mayor capacidad para transmitir valores.

Para identificar los cinco que mostraban dicha característica se realizó un pretest aplicando el siguiente procedimiento:

Ocho investigadores del equipo se expusieron y evaluaron la carga de valores percibida en cada uno de los 68 anuncios televisivos de la muestra global.

Cada uno de los investigadores valoró individualmente (en los 68 anuncios) la presencia y el grado de intensidad percibidos respecto al inventario de valores que sería utilizado durante el test.

Para evaluar los anuncios cada investigador debía asignar la siguiente puntuación a cada uno de los 25 valores del inventario: ninguna $=0$; leve $=1 ;$ media $=2 ;$ alta $=3$.

El sumatorio global de la puntuación asignada a cada uno de los 68 anuncios por los ocho investigadores expresaba (de mayor a menor) la capacidad de los 68 anuncios para transmitir valores, sobre un rango de 71 a 250 puntos.

Los anuncios seleccionados para desarrollar el test de recepción fueron los siguientes:

- Visit Madrid. Juntos nunca hemos perdido. Gracias, Madrid (250 puntos). $<$ https://www.youtube.com/watch?v=VgdeD3fNUag>.

- Florette. Orgullosos de ti (246 puntos). $<$ https://www.youtube.com/watch?v=tLaEfrtpVdw>.

- Fundación Bancaria BBK. Ser mayor nunca fue tan importante (233 puntos).

<https://www.youtube.com/watch?v=xlL-OtK3IF4\&feature=emb_ title>.

5. El 85\% de los españoles afirmó que se informaba a través de la televisión. La prensa en línea y los comunicados de fuentes oficiales se situaron en la segunda y la tercera posiciones, con un 54\% y un 53\% respectivamente (Business Insider, 2020). 
- Volkswagen. Juntos también en este viaje (221 puntos). $<$ https://www.youtube.com/watch?v=LkUAetPG-G4 $>^{6}$.

- Ministerio de Sanidad. Este virus lo paramos unidos (206 puntos). $<$ https://www.youtube.com/watch?time_continue=3\&v=b6Fgddtx6a w\&feature=emb_title $>$.

\subsection{Selección de la muestra de sujetos}

Puesto que ninguno de los objetivos de esta investigación pretendía representar a un tipo de población o a un grupo humano concretos, se consideró pertinente recurrir a un muestreo de conveniencia para seleccionar los sujetos que serían expuestos en el test destinado a medir la carga de valores transmitida por los anuncios.

La literatura científica revisada señala la relación en la evolución de los valores con las diferencias de edad (Konty y Chorn Dunham, 1997); las diferencias de sexo y de generación (Yagüe López et al., 2013); la coyuntura económica (Inglehart y Baker, 2000; Veira et al., 2010); la persistencia de los valores de la religión (Inglehart y Baker, 2000), y las situaciones de crisis (Torralba Rosselló, 2010; Sortheix et al., 2019). Se consideró, en consecuencia, que la muestra debería estar compuesta por sujetos con una gama de edades extensa, de ambos sexos, provenientes de lugares con coyunturas económicas claramente distintas, de diferentes religiones y que pudiesen ser diferenciados respecto a alguna experiencia intensa relacionada con la pandemia.

Para lograr una muestra de conveniencia con estas características se utilizó el método "bola de nieve», haciendo llegar el test a 542 personas cuyos edad, sexo, origen y experiencia respecto a la crisis sanitaria pudiesen ser explorados y analizados a partir de las primeras preguntas de la prueba, es decir, a partir de las diez variables que fueron introducidas en el cuestionario para definir el perfil de los sujetos.

El test fue respondido, finalmente, por un total de 470 sujetos, con una gama de edades entre 14 y más de 65 años, de los cuales 175 eran hombres y 295, mujeres; 99 españoles, 7 de otros países de la Comunidad Europea, 346 de Latinoamérica, 1 africano, 1 asiático y 16 de otros orígenes. Respecto a la pertenencia religiosa, 261 manifestaron ser católicos, 26 de otra confesión cristiana, 105 ateos, 2 judíos, 14 de otras religiones y 62 no respondieron.

6. Este vídeo fue eliminado de YouTube por Volkswagen en fechas posteriores al desarrollo de este estudio por razones que desconocemos. El vídeo mostraba un extenso y soleado paisaje de colinas verdes junto al mar y una carretera ondulante por la que circulaba un vehículo; mientras, sonaba una agradable música de fondo y una voz en off hablaba de los viajes que podríamos hacer tras recuperar de nuevo la libertad. 


\subsection{Sobre la herramienta aplicada}

El inventario de valores utilizado en esta investigación está compuesto por los 25 valores siguientes: amistad, bienestar, cooperación, cultura, deberes, democracia, derechos, dignidad, esfuerzo, educación, familia, identidad, igualdad, independencia, intimidad, justicia-equidad, libertad, moral-honor, orden, paz, pluralismo, progreso, respeto, responsabilidad y salud.

El procedimiento seguido para desarrollar el test de recepción se basó en hacer llegar a las personas evaluadoras una invitación ${ }^{7}$ a través de algún canal en línea con una breve explicación sobre la investigación y el enlace que daba acceso a ProtocoloEva ${ }^{\oplus 8}$.

Cuando un evaluador o una evaluadora accede a ProtocoloEva ${ }^{\oplus}$ debe pasar por dos etapas previas de entrenamiento: asistir al vídeo tutorial y responder un primer test de entrenamiento. Los sujetos valoraron cinco anuncios en total, y los datos de la primera evaluación (en este caso los del anuncio del Ministerio de Sanidad) fueron los del entrenamiento, por lo que no se consideraron válidos.

Antes de empezar a responder al test, cada evaluador debía contestar varias preguntas sobre su perfil sociodemográfico. Se pidió información sobre las cuestiones siguientes (tabla 1).

Tabla 1. Variables sociodemográficas

\begin{tabular}{|c|c|}
\hline Variables & Categorias de la variable \\
\hline Sexo: & hombre, mujer, prefiero no responder. \\
\hline Edad: & 14-18, 20-24, 25-34, 35-44, 45-54, 55-64, 65 o más. \\
\hline Estado civil: & soltero/a, casado/a, divorciado/a, viudo/a, pareja de hecho. \\
\hline Nivel de estudios: & $\begin{array}{l}\text { sin estudios, primarios, secundarios, profesionales, } \\
\text { universitarios. }\end{array}$ \\
\hline Ingresos mensuales en $€$ : & $\begin{array}{l}\text { sin ingresos, 500, 500-999, 1000-1.999, 2.000-2.999, } 3.000 \text { o } \\
\text { más. }\end{array}$ \\
\hline Ocupación: & $\begin{array}{l}\text { estudiante, profesional autónomo, empresario/a, pensionista, } \\
\text { empleado/a de empresa pública o privada, tareas del hogar, } \\
\text { desempleado/a. }\end{array}$ \\
\hline Lugar de nacimiento: & $\begin{array}{l}\text { España, otro país de la Comunidad Europea, Latinoamérica, } \\
\text { África, Asia, otros. }\end{array}$ \\
\hline Religión: & $\begin{array}{l}\text { Católica, otra confesión cristiana, musulmana, judía, otras, } \\
\text { ateo/a, prefiero no responder. }\end{array}$ \\
\hline $\begin{array}{l}\text { ¿Cuándo ha respondido a este } \\
\text { test?: }\end{array}$ & $\begin{array}{l}\text { durante el periodo de alarma por la epidemia de COVID-19, } \\
\text { después del periodo de alarma por la epidemia de COVID-19. }\end{array}$ \\
\hline $\begin{array}{l}\text { ¿Ha fallecido alguna persona muy } \\
\text { querida de su entorno por causa } \\
\text { de la epidemia de COVID-19?: }\end{array}$ & no, sí. \\
\hline
\end{tabular}

Fuente: elaboración propia.

7. Ver el anexo 1.

8. A través del enlace <https://a-eva.org/protocolo-eva/> el lector puede acceder a un ejemplo que aplica este mismo procedimiento. 


\subsection{Sobre las escalas de medición}

Los resultados numéricos de ProtocoloEva expresan qué valores ha comunicado el anuncio y con qué intensidad lo ha hecho. Estos resultados constituyen una variable continua, con un rango de $(-3)$ a $(+3)$ para cada uno de los valores percibidos. Los valores extremos expresan que el mensaje es radicalmente contrario $(-3)$ o radicalmente favorable $(+3)$ a un valor determinado. El resultado (0) indica que el valor medido está justo en el punto de equilibrio, es decir, que el mensaje transmite en el mismo grado elementos favorables y desfavorables al valor evaluado.

En la figura 1 puede verse el funcionamiento de la escala de medición. La imagen muestra las potencias con las que el anuncio de Fundación Bancaria BBK ha comunicado los 25 valores analizados en el grupo de 470 personas receptoras.

Figura 1. Valores percibidos en el anuncio de Fundación Bancaria BBK

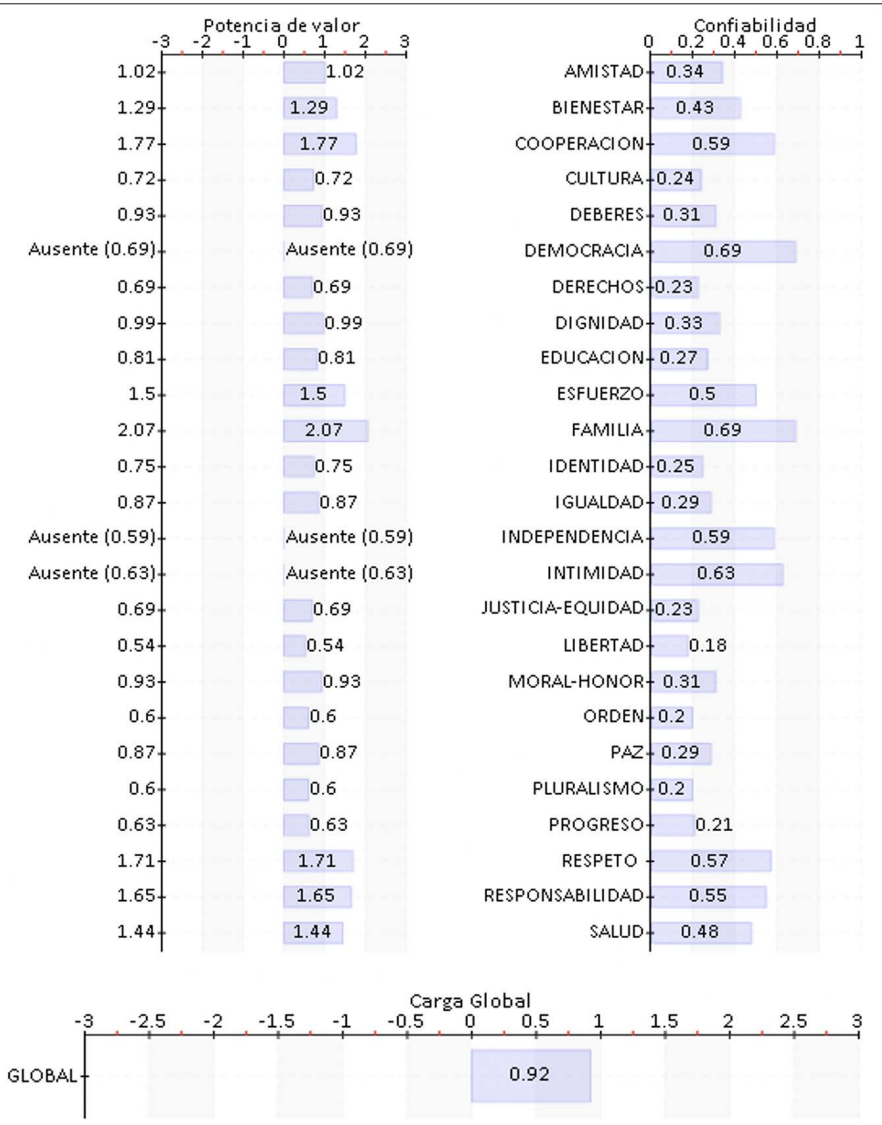

Fuente: tabla generada por el aplicativo ProtocoloEva. 
En la figura 1 aparecen las potencias de valor (columna de la izquierda); las confiabilidades (columna de la derecha) y la carga global (escala horizontal inferior). Observando estas tres escalas podemos ver valores ausentes (democracia, independencia e intimidad), lo que nos indica que la mayoría de sujetos informaron de que esos valores no fueron percibidos en el anuncio; valores con potencia negativa (no aparece ninguno), lo cual informaría de que la mayoría de receptores han considerado los contenidos del anuncio como contrarios a esos valores, y valores con potencia positiva, es decir, aquellos respecto a los que los contenidos son favorables.

La escala potencia de valor (columna izquierda) mide la intensidad con la que los sujetos han percibido cada uno de los valores mediante un algoritmo basado en la moda y ponderado por la confiabilidad. Su rango puede oscilar entre $(-3)$ y $(+3)$. La escala confiabilidad (columna de la derecha) informa mediante un índice (entre 0 y 1 ) sobre cuál es el porcentaje de sujetos que coincidieron en valorar exactamente en el mismo punto de una escala de siete grados la potencia percibida de un determinado valor respecto al inventario total de 25 valores. Finalmente, la escala carga global expresa en una única cifra, también con un rango de $(-3)$ a $(+3)$, la suma algebraica de todas las potencias de valor dividida por el número total de valores del inventario (25) (Rodríguez Bravo et al., 2013: 176).

La investigación en la que se validó la metodología para localizar el inventario de valores y el procedimiento para medir su recepción fue publicado en Rodríguez Bravo et al. (2013 y 2017).

\section{Resultados}

Los resultados obtenidos se basan en la evaluación de cuatro anuncios publicitarios por 470 sujetos, es decir, en las repuestas a $470 \times 4=1.880$ test de recepción, y, puesto que cada prueba de recepción supuso medir el grado de presencia de 25 valores, se apoyan en el análisis de $1.880 \times 25=47.000$ mediciones.

En el anexo 2 pueden revisarse los resultados completos sobre percepción de valores para los cuatro anuncios de la muestra investigada.

\subsection{Análisis de tendencias generales}

Para identificar las tendencias generales de la publicidad analizada durante la pandemia de covid-19 se realizó un análisis comparativo de todas las cargas globales de valor obtenidas en los anuncios estudiados y se ha confrontado esta información con la revisión de todas las potencias de valor percibidas en los cuatro anuncios, segmentadas en función de las variables independientes.

Los datos que muestra la figura 2 indican que la capacidad de los cuatro anuncios para comunicar valores es relativamente alta y muy homogénea.

En la figura 3 puede observarse la distribución de las respectivas potencias de valor que ha logrado transmitir cada uno de los anuncios. 
Figura 2. Cargas globales de valor

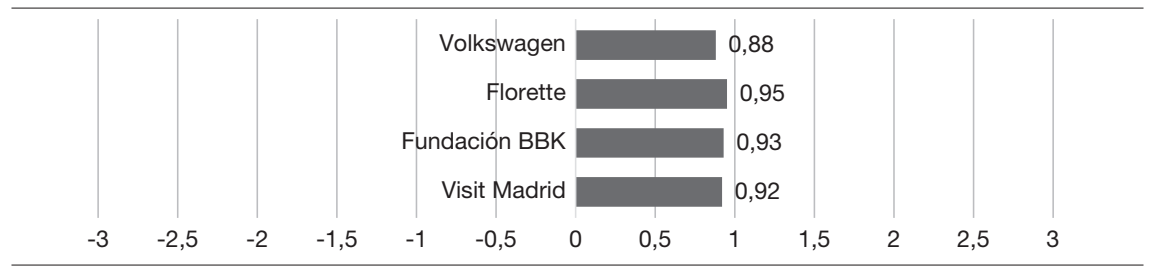

Fuente: elaboración propia.

Figura 3. Potencias de valor de los cuatro anuncios analizados ${ }^{9}$

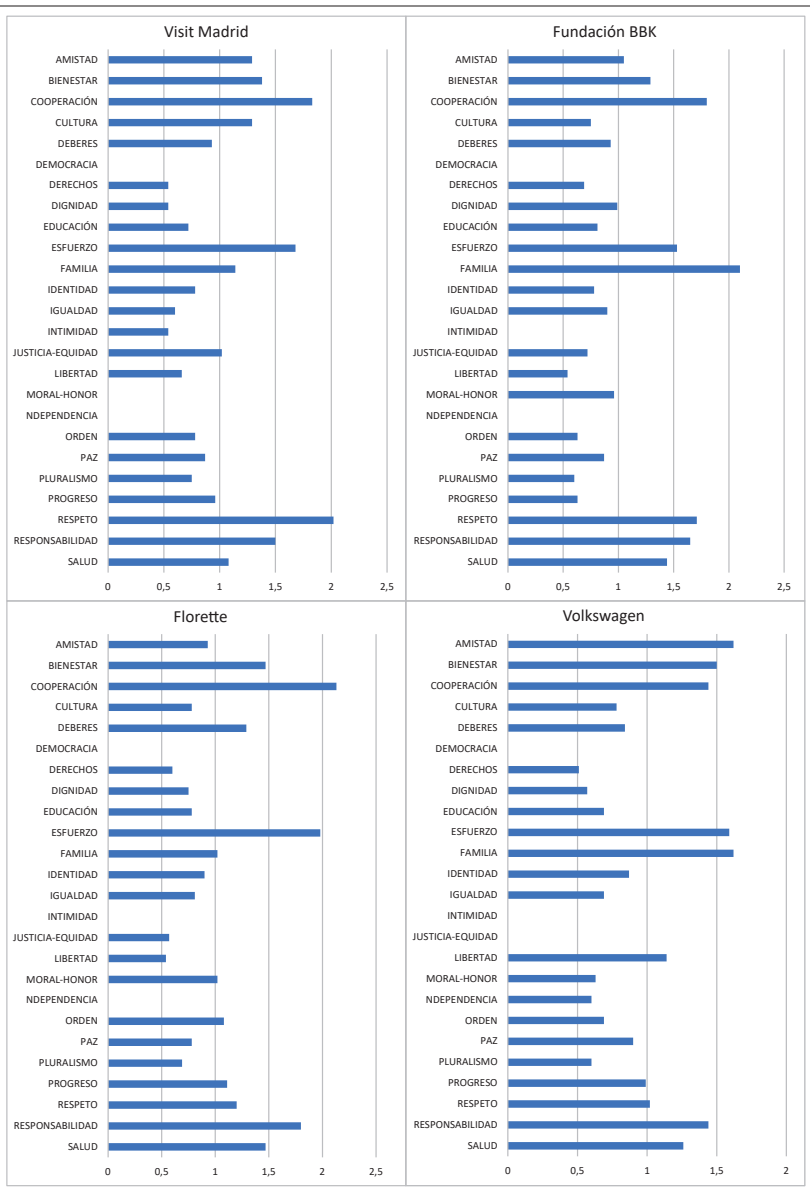

Fuente: elaboración propia.

9. Para facilitar la comparación visual en esta imagen se omiten las zonas negativas de las escalas y se reduce la presentación del rango real $(-3$ hasta +3$)$ solamente a la zona numérica positiva $(0$ hasta $+2,5)$ sobre la que se extienden los datos recopilados. 
Comparando los gráficos de barras de la figura 3 puede verse la fuerte coherencia entre los cuatro perfiles. Los valores comunicados por los cuatro anuncios muestran una clara orientación global positiva. Si bien hay entre ellos algunas diferencias relevantes que se revisan más adelante, todos los anuncios han comunicado, con potencia alta, los valores cooperación, bienestar, esfuerzo, familia, salud, respeto y responsabilidad, y no han comunicado los valores democracia, intimidad e independencia. Por último, los anuncios han transmitido con una intensidad claramente menor los valores derechos, justicia-equidad, dignidad y libertad.

\subsection{Valores dominantes}

Se entienden aquí por "valores dominantes» aquellos que han sido percibidos con mayor intensidad. Para localizarlos se analizaron las potencias de valor acumuladas por los cuatro anuncios para cada uno de los 25 valores estudiados.

Figura 4. Potencias de valor acumuladas

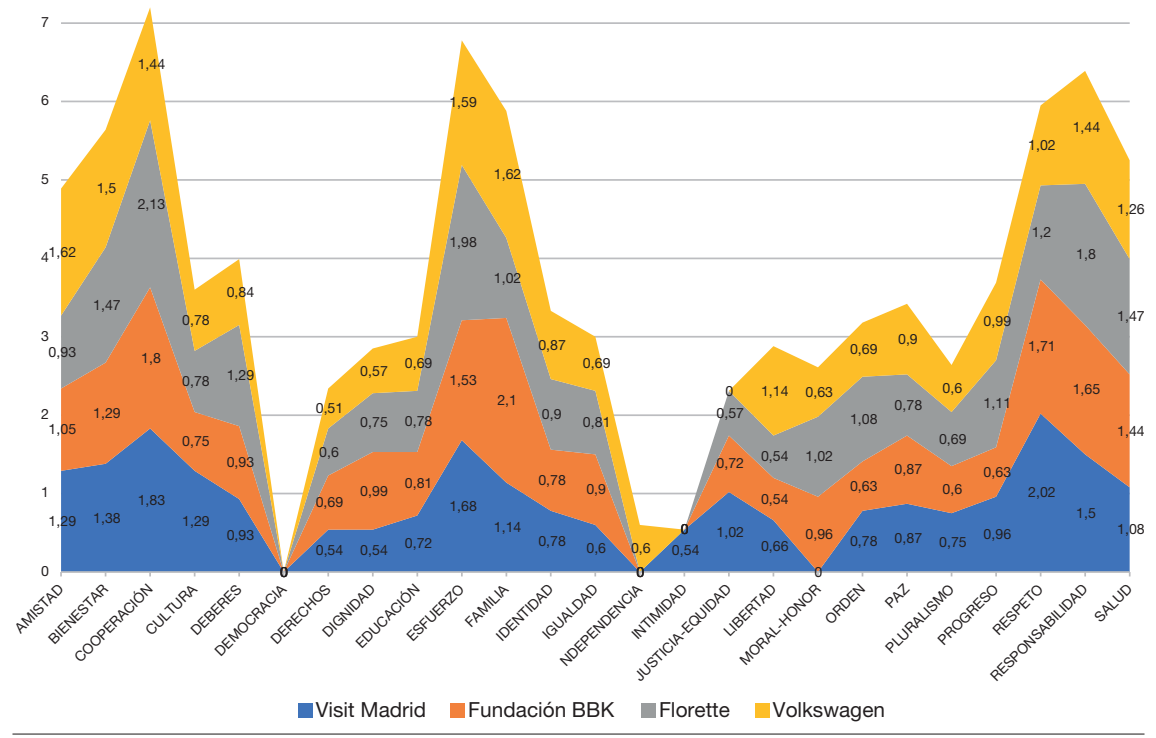

Fuente: elaboración propia.

Los puntos más altos del perfil de la figura 4 muestran que los valores percibidos con mayor potencia fueron los de cooperación, esfuerzo, responsabilidad, respeto, familia, bienestar y salud. 
Tabla 2. Potencia de valor acumulada por los valores dominantes

\begin{tabular}{|c|c|c|c|c|c|}
\hline \multirow{2}{*}{$\begin{array}{c}\text { VALORES } \\
\text { DOMINANTES }\end{array}$} & \multicolumn{4}{|c|}{ ANUNCIOS } & \multirow{2}{*}{$\begin{array}{l}\text { POTENCIA } \\
\text { ACUMULADA }\end{array}$} \\
\hline & Visit Madrid & Fundación BBK & Florette & Volkswagen & \\
\hline COOPERACIÓN & 1,83 & 1,8 & 2,13 & 1,44 & 7,2 \\
\hline ESFUERZO & 1,68 & 1,53 & 1,98 & 1,59 & 6,78 \\
\hline RESPONSABILIDAD & 1,5 & 1,65 & 1,8 & 1,44 & 6,39 \\
\hline RESPETO & 2,02 & 1,71 & 1,2 & 1,02 & 5,95 \\
\hline FAMILIA & 1,14 & 2,1 & 1,02 & 1,62 & 5,88 \\
\hline BIENESTAR & 1,38 & 1,29 & 1,47 & 1,5 & 5,64 \\
\hline SALUD & 1,08 & 1,44 & 1,47 & 1,26 & 5,25 \\
\hline
\end{tabular}

Fuente: elaboración propia.

La tabla 2 muestra las potencias de los siete valores dominantes. De izquierda a derecha encontramos los nombres de los valores, las potencias de valor de los cuatro anuncios y el resultado de las sumas horizontales (potencia acumulada). Resulta llamativo observar que el valor salud muestre la potencia acumulada más baja de la lista.

Tabla 3. Análisis de la confiabilidad

\begin{tabular}{lccccc}
\hline \multicolumn{1}{c}{ VALORES } & \multicolumn{5}{c}{ ANUNCIO } \\
\cline { 2 - 6 } DOMINANTES & Visit Madrid & Fundación BBK & Florette & Volkswagen & C. MEDIA \\
\hline COOPERACIÓN & 0,6 & 0,59 & 0,7 & 0,48 & 0,59 \\
ESFUERZO & 0,56 & 0,5 & 0,66 & 0,52 & 0,56 \\
RESPONSABILIDAD & 0,51 & 0,55 & 0,61 & 0,48 & 0,54 \\
RESPETO & 0,33 & 0,57 & 0,39 & 0,33 & 0,41 \\
FAMILIA & 0,38 & 0,69 & 0,34 & 0,54 & 0,49 \\
BIENESTAR & 0,46 & 0,43 & 0,48 & 0,5 & 0,47 \\
SALUD & 0,36 & 0,48 & 0,49 & 0,42 & 0,44 \\
C. MEDIA & 0,46 & 0,54 & 0,52 & 0,47 & \\
\hline
\end{tabular}

Fuente: elaboración propia.

La tabla 3 muestra el grado de confiabilidad (coherencia entre respuestas) de los anuncios para los siete valores dominantes y, en la columna de la derecha, las medias aritméticas de estas confiabilidades respecto a los anuncios y a los valores.

Estos datos (entre 0,41 y 0,59 ) indican que entre un $41 \%$ y un $59 \%$ de los sujetos, al evaluar un anuncio, eligieron el mismo punto sobre una escala de siete grados de libertad $(-3,-2,-1,0,1,2,3)$ al juzgar la presencia y la intensidad percibidas de cada valor. Teniendo en cuenta que la probabilidad de coincidencia al azar entre distintos sujetos es de 0,14 (un 14\% de los sujetos), este dato informa de la alta fiabilidad en los resultados del test para estos siete valores. 


\subsection{Influencia del perfil de los sujetos en la recepción de los valores}

Para explorar la influencia de los rasgos sociodemográficos sobre la recepción de los valores se analizaron las cargas globales de valores, separándolas por sus categorías de segmentación. Este análisis se realizó para todos los rasgos (ver tabla 1), con excepción del noveno ${ }^{10}$.

Tabla 4. Análisis de las cargas globales de valores

\begin{tabular}{|c|c|c|c|}
\hline \multicolumn{4}{|c|}{ Análisis de las cargas globales de valores } \\
\hline & \multicolumn{3}{|c|}{$\begin{array}{l}\text { Por sexo } \\
\end{array}$} \\
\hline ANUNCIOS & Hombres & Mujeres & Diferencia: \\
\hline Visit Madrid & 0,94 & 0,93 & 0,01 \\
\hline Fundación BBK & 0,91 & 0,96 & $-0,05$ \\
\hline Florette & 0,9 & 0,97 & $-0,07$ \\
\hline \multirow[t]{2}{*}{ Volkswagen } & 0,88 & 0,89 & $-0,01$ \\
\hline & \multicolumn{3}{|c|}{ Por edad } \\
\hline ANUNCIOS & De 14 a 44 & De $45 a>65$ & Diferencia: \\
\hline Visit Madrid & 0,96 & 0,39 & 0,57 \\
\hline Fundación BBK & 0,96 & 0,54 & 0,42 \\
\hline Florette & 0,98 & 0,54 & 0,44 \\
\hline \multirow[t]{2}{*}{ Volkswagen } & 0,93 & 0,42 & 0,51 \\
\hline & \multicolumn{3}{|c|}{ Por estado civil } \\
\hline ANUNCIOS & Solteros/as & Otros & Diferencia: \\
\hline Visit Madrid & 0,97 & 0,69 & 0,28 \\
\hline Fundación BBK & 0,96 & 0,65 & 0,31 \\
\hline Florette & 0,98 & 0,73 & 0,25 \\
\hline \multirow[t]{2}{*}{ Volkswagen } & 0,93 & 0,6 & 0,33 \\
\hline & \multicolumn{3}{|c|}{ Por nivel de estudios } \\
\hline ANUNCIOS & Universitarios/as & Otros & Diferencia: \\
\hline Visit Madrid & 0,93 & 0,79 & 0,14 \\
\hline Fundación BBK & 0,93 & 0,85 & 0,08 \\
\hline Florette & 0,92 & 1,06 & $-0,14$ \\
\hline \multirow[t]{2}{*}{ Volkswagen } & 0,9 & 0,82 & 0,08 \\
\hline & \multicolumn{3}{|c|}{ Por nivel de ingresos } \\
\hline ANUNCIOS & $<1000 €$ & $>999 €$ & Diferencia: \\
\hline Visit Madrid & 0,97 & 0,71 & 0,26 \\
\hline Fundación BBK & 0,98 & 0,67 & 0,31 \\
\hline Florette & 1,01 & 0,65 & 0,36 \\
\hline Volkswagen & 0,93 & 0,68 & 0,25 \\
\hline
\end{tabular}

10. Esta variable, planteada a partir de la pregunta: «¿Cuándo ha respondido Vd. a este test: durante el periodo de alarma o después del periodo de alarma?», fue incorporada pensando en el desarrollo futuro de una segunda fase de investigación. 


\begin{tabular}{lccc}
\hline & \multicolumn{3}{c}{ Por ocupación } \\
\hline ANUNCIOS & Estudiantes & Otras & Diferencia: \\
\hline Visit Madrid & 1 & 0,68 & 0,32 \\
Fundación BBK & 0,99 & 0,71 & 0,28 \\
Florette & 1,04 & 0,6 & 0,44 \\
Volkswagen & 1,01 & 0,54 & 0,47 \\
\hline \multicolumn{4}{c}{ Por lugar de nacimiento } \\
\hline ANUNCIOS & España & Iberoamérica & Diferencia: \\
\hline Visit Madrid & 0,32 & 1,04 & $-0,72$ \\
Fundación BBK & 0,45 & 1,03 & $-0,58$ \\
Florette & 0,37 & 1,12 & $-0,75$ \\
Volkswagen & 0,34 & 1,03 & $-0,69$ \\
\hline \multicolumn{4}{c}{ Por religión } \\
\hline ANUNCIOS & Cristianos & Ateos & Diferencia: \\
\hline Visit Madrid & 1,08 & 0,47 & 0,61 \\
Fundación BBK & 1,09 & 0,59 & 0,5 \\
Florette & 1,14 & 0,49 & 0,65 \\
Volkswagen & 1,08 & 0,47 & 0,61 \\
\hline & & Por duelo de alguien muy querido \\
\hline ANUNCIOS & Sí & No & Diferencia: \\
\hline Visit Madrid & 0,44 & 0,96 & $-0,52$ \\
Fundación BBK & 0,4 & 0,97 & $-0,57$ \\
Florette & 0,36 & 0,98 & $-0,62$ \\
Volkswagen & 0,33 & 0,91 & $-0,58$ \\
\hline
\end{tabular}

Fuente: elaboración propia.

La tabla 4 muestra la carga global de valores comunicada por los cuatro anuncios televisivos, estudiando su recepción según el sexo, la edad, la ocupación, la religión, etc. Con el objetivo de localizar las variables más influyentes, los resultados se presentan comparando los dos grupos de sujetos más diferenciados entre sí. Por ejemplo, las siete franjas de edad en las que se pedía a los receptores que se ubicaran se han agrupado solo en dos: de 14 a 44 años y de 45 años a más de 65.

Las cifras de la columna de la derecha son el resultado de restar los datos entre la primera y la segunda columna, es decir, la diferencia entre cargas globales de valor. Se configuran tres niveles de influencia, según las diferencias observadas sean inferiores a 0,1 ; oscilen de 0,1 a 0,4 , o sean superiores a 0,4 . A partir de aquí, estos tres grados se denominarán: influencia irrelevante, influencia baja o influencia intensa.

Así, en la transmisión de los valores relacionados con la pandemia provocada por la covid-19, el lugar de nacimiento (España o Latinoamérica), la religión y la circunstancia de haber sufrido el fallecimiento de alguien muy querido por causa de la epidemia tienen una influencia alta; el estado civil, el nivel de estudios, el nivel de ingresos y la ocupación tienen una influencia baja, y el sexo de los receptores tiene una influencia irrelevante. 
En los apartados siguientes se expondrán solamente los resultados relacionados con las variables que han sido identificadas como de influencia alta.

\subsubsection{Influencia de la edad}

Para estudiar la influencia de la edad en la comunicación de los valores se revisó su desglose en las siete franjas de edad.

Figura 5. Carga global desglosada por franjas de edad

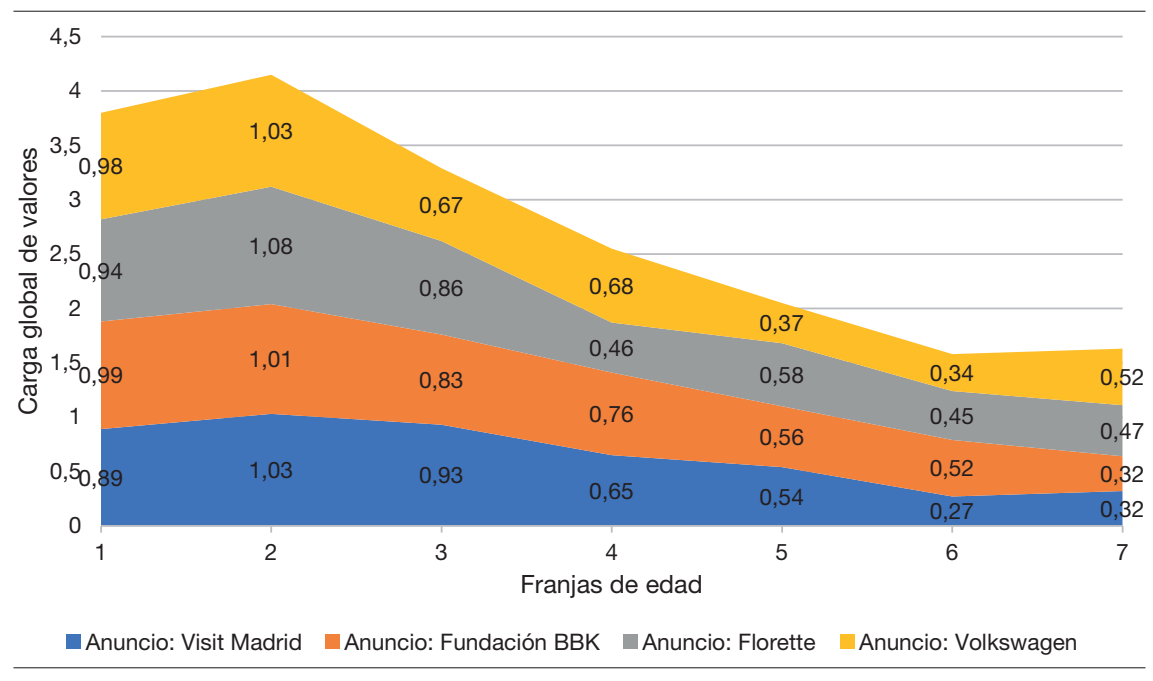

Fuente: elaboración propia.

En la figura 5, donde se presentan las cargas globales de valores comunicados como áreas apiladas, la máxima predisposición de los sujetos para identificar y percibir los valores aparece entre los 20 y los 24 ańos. Y puede observarse una disminución progresiva del nivel de valores percibido hasta los 55 , donde ya se estabiliza.

\subsubsection{Influencia del lugar de origen}

La estrategia utilizada para observar si el desarrollo económico-social influye en la recepción de los valores fue diferenciar a los evaluadores españoles de los provenientes de otras grandes zonas geográficas. Se buscaba analizar dos categorías de sujetos: los españoles y los latinoamericanos, considerando que el grado de desarrollo del contexto socioeconómico (muy favorable a España) podía ser un factor determinante para la percepción de los valores. 
Figura 6. Carga global de valores percibida por españoles y por latinoamericanos

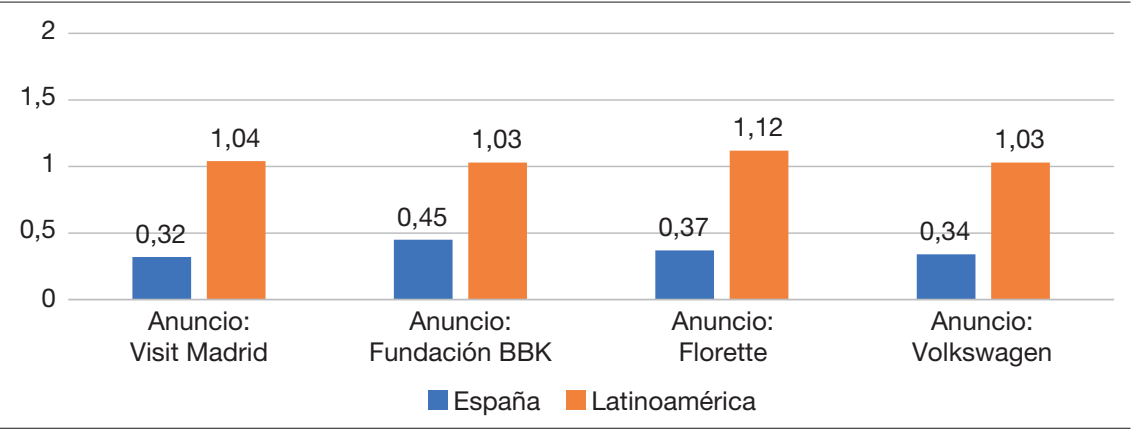

Fuente: elaboración propia.

La figura 6 muestra una fuerte diferencia entre los evaluadores de ambos orígenes, tanto en el número de valores identificados como en la intensidad con la que han sido percibidos. Los resultados indican una receptividad a los valores casi cuatro veces inferior en los receptores españoles.

\subsubsection{Influencia de la religión}

Para estudiar la influencia de la religión se compararon las cargas globales de valor percibidas entre los evaluadores de dos perfiles religiosos diferentes. Concretamente, se compararon cristianos con ateos.

Figura 7. Carga global de valores percibida por cristianos y por ateos

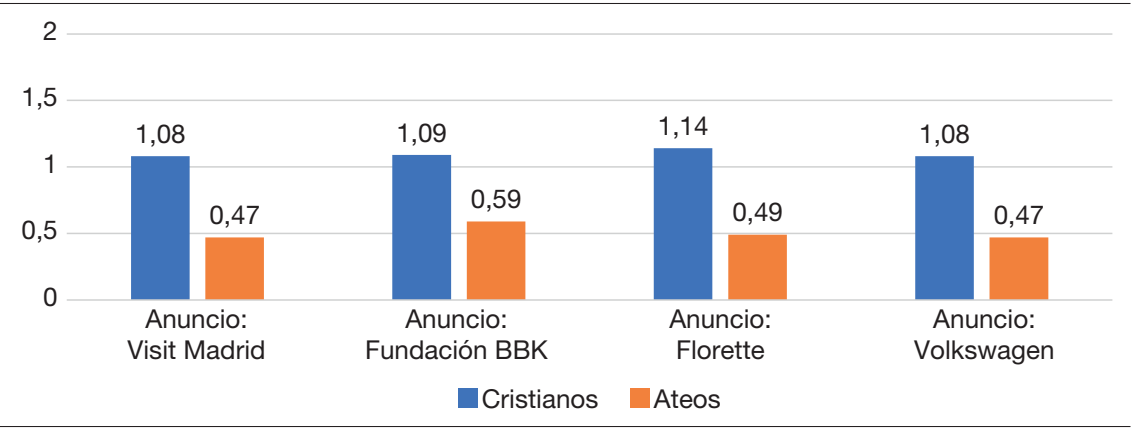

Fuente: elaboración propia.

La figura 7 presenta los resultados de la comparación entre los participantes que manifestaron ser cristianos y los que se declararon ateos. Los cristianos resultaron ser mucho más receptivos hacia los valores que los ateos.

Los resultados expresan una fuerte diferencia, en el sentido de que el hecho de ser cristianos llega a triplicar la receptividad a los valores. 


\subsubsection{Influencia del duelo}

La influencia de la muerte de personas muy queridas del entorno por causa de la pandemia se analizó utilizando el mismo procedimiento aplicado en las dos variables anteriores. El objetivo de introducir la circunstancia del duelo fue indagar sobre el potencial de las experiencias intensas de crisis en la recepción de los valores.

El diagrama de barras de la figura 8 muestra los resultados de la comparación entre los evaluadores que manifestaron haber perdido una persona muy querida y los que no vivieron esa experiencia.

Figura 8. Carga global de valores percibida según los sujetos hayan experimentado, o no, duelo por alguien muy querido de su entorno

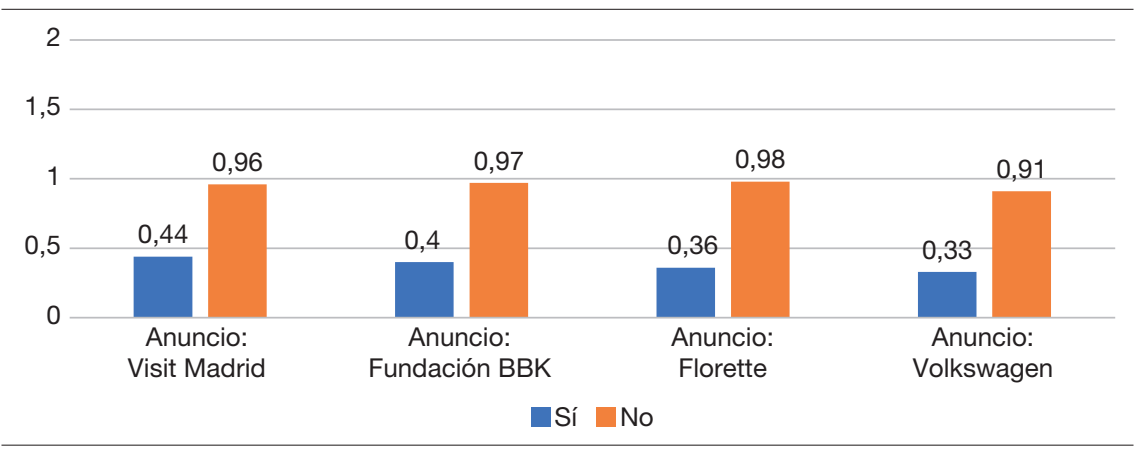

Fuente: elaboración propia.

Como puede verse en la figura 8, quienes perdieron a un ser querido han percibido una carga global de valores casi tres veces menor que las que no vivieron esa pérdida.

\subsection{Estrategias comunicativas asociadas a los valores}

Para localizar las estrategias comunicativas asociadas a los valores que han utilizado las fuentes emisoras se cruzaron dos tipos de análisis: el análisis de las potencias de valor y el de la confiabilidad (figura 9). El procedimiento se desarrolló en tres etapas:

1. Localización de los tres valores percibidos con mayor potencia para cada uno de los anuncios.

2. Localización de los tres valores de mayor confiabilidad para cada uno de los anuncios.

3. Localización de las coincidencias entre las mayores potencias de valor comunicadas y las confiabilidades más altas.

El objetivo de esta exploración era identificar, para cada anuncio, valores con los que la fuente emisora había logrado mayor eficacia comunicativa, es 
decir, los transmitidos con intensidad más alta, y había conseguido una percepción más coherente.

Figura 9. Análisis de las estrategias comunicativas

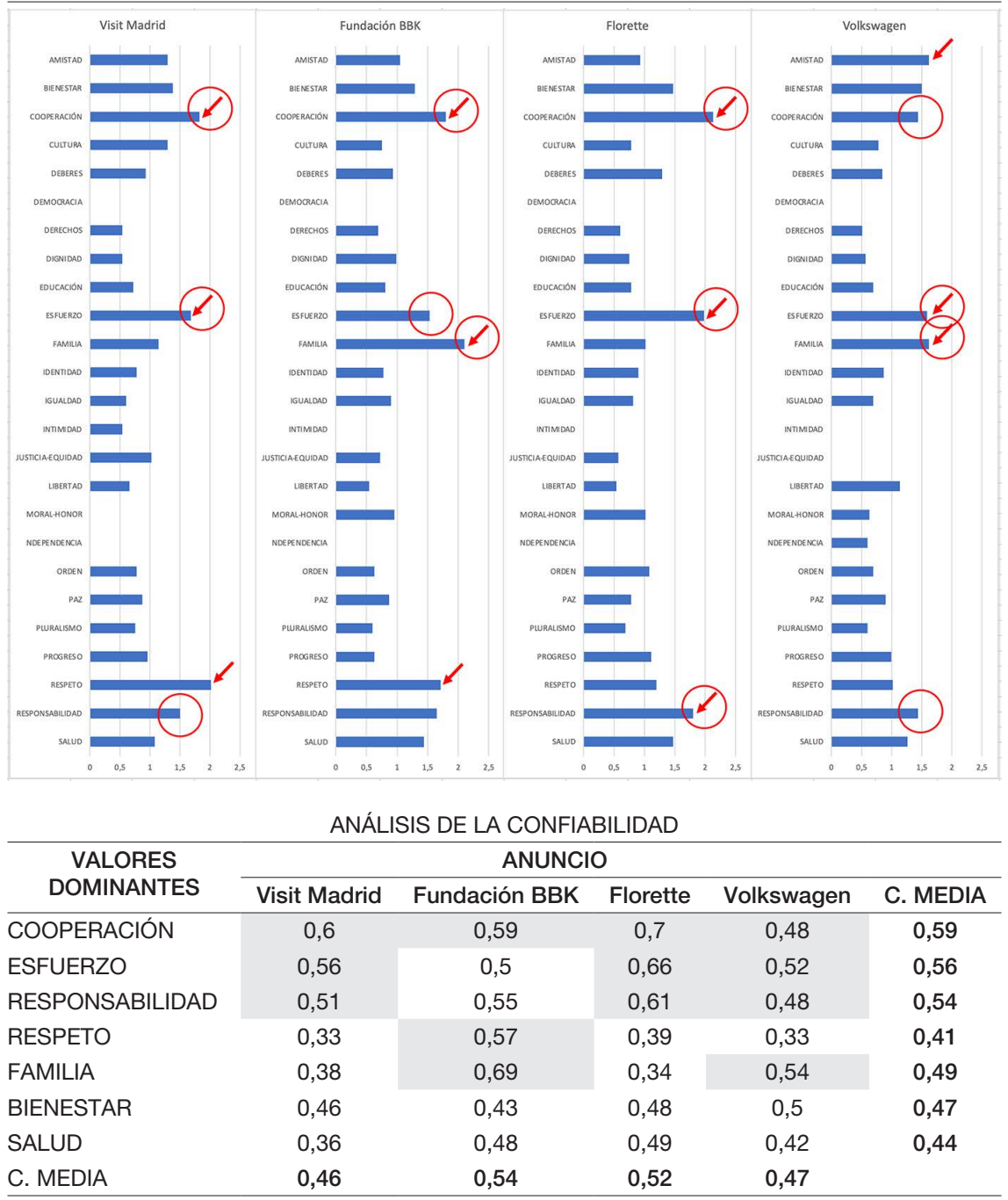

Fuente: elaboración propia.

La figura 9, en la parte superior, muestra los gráficos de barras con las potencias de valor de los cuatro anuncios; doce flechas rojas que indican las tres mayores potencias de valor comunicadas por cada anuncio, y trece círculos señalando los tres o cuatro valores de confiabilidad más alta para cada anuncio. En la parte inferior encontramos la tabla de análisis de la confiabilidad, 
en la que están resaltados en color gris los datos que indican los tres niveles más altos de confiabilidad para cada anuncio.

La coincidencia entre las flechas (alta potencia de valor) y los círculos (alta confiabilidad) es lo que permite localizar los valores comunicados con mayor eficacia. La alta homogeneidad que muestra el perfil de los cuatro gráficos prueba que las estrategias comunicativas de las cuatro fuentes han sido muy similares. El análisis muestra, también, algunas diferencias entre los cuatro anuncios.

Tabla 5. Valores comunicados con mayor eficacia por las fuentes

\begin{tabular}{lcccc}
\hline \multicolumn{5}{c}{ Anuncios } \\
\hline Valores & Visit Madrid & Fundación BBK & Florette & Volkswagen \\
\cline { 2 - 5 } estratégicos & Cooperación & Familia & Cooperación & Familia \\
& $(1,83)$ & $(2,1)$ & $(2,13)$ & $(1,62)$ \\
& Esfuerzo & Cooperación & Esfuerzo & Esfuerzo \\
& $(1,68)$ & $(1,8)$ & $(1,98)$ & $(1,59)$ \\
& (sin coincidencia) & $($ sin coincidencia) & Responsabilidad & Amistad \\
& & & $(1,8)$ & $(1,62)$ \\
\hline
\end{tabular}

Fuente: elaboración propia.

La tabla 5 presenta los valores comunicados por las fuentes con mayor eficacia comunicativa. Mientras el Ayuntamiento de Madrid reparte su mensaje entre los valores cooperación y esfuerzo; la Fundación Bancaria BBK lo concentra en el valor familia; la empresa Florette, en el valor cooperación, y Volkswagen lo distribuye entre familia, esfuerzo y amistad.

Es interesante observar que el valor amistad, percibido con intensidad alta en el anuncio de Volkswagen, no forma parte de los que en el análisis del apartado 4.2 habían sido identificados como valores dominantes. No obstante, al revisar la tabla 4, resulta evidente la alta coincidencia en los valores cooperación, esfuerzo y familia de los cuatro anuncios.

\section{Conclusiones}

Objetivo 1:

Los resultados indican que los anunciantes han comunicado valores para resistir y apoyar el sacrificio y las renuncias exigidos por la situación de confinamiento, pero han eludido los valores contra los que atentaban esas mismas duras normativas de reclusión domiciliaria.

La ausencia casi total del valor intimidad, a pesar de la fuerte carga de contenidos con actividades hogareñas, parece explicable por el rechazo de los receptores a una intromisión de las marcas en actividades que se suelen desarrollar de manera privada, para mostrarlas públicamente.

Objetivo 2:

Los valores dominantes fueron: cooperación, esfuerzo, responsabilidad, respeto, familia, bienestar y salud. El valor salud muestra el índice de poten- 
cia acumulada más bajo. Y se han transmitido con una potencia claramente menor los valores derechos, justicia-equidad, dignidad y libertad.

La medición realizada muestra que las fuentes emisoras no han establecido en sus mensajes una conexión directa con la parte más trágica y dramática de la crisis: el gran deterioro de la salud global que esta implica. Eludiendo claramente esta cuestión.

\section{Objetivo 3:}

Este estudio muestra la disminución progresiva del nivel de valores percibidos a medida que aumenta la edad, lo que parece ser un reflejo de la desconfianza en la publicidad a medida que envejecemos, que pasa a disminuir un 50\% entre los 20 y los 55 años.

Los evaluadores españoles percibieron una carga global media de valores de un $64,7 \%$ menor que los latinoamericanos. Se observa, también, una fuerte diferencia entre las personas cristianas y las ateas, pudiéndose afirmar que el hecho de ser creyentes duplica la receptividad a los valores (un 183,8\% superior). La coherencia entre ambos resultados permite deducir que la mayor religiosidad de los participantes latinoamericanos, frente al ateísmo dominante de los españoles, es lo que determina esa fuerte diferencia de receptividad frente a los valores humanos.

Los evaluadores que experimentaron la experiencia del fallecimiento por covid-19 de una persona muy cercana resultaron ser mucho menos receptivos (un 60\% menor) hacia los valores. Este resultado indica la aparición de un intenso escepticismo de las personas que experimentaron el duelo, frente al discurso publicitario eufórico y buenista.

Objetivo 4:

Los datos muestran que las estrategias de las fuentes emisoras respecto a los valores han sido muy similares, coincidiendo en centrarse en los valores cooperación, esfuerzo y familia, con un alto grado de superposición. Este resultado permite deducir que los anunciantes, realmente, dejaron de lado las estrategias y los criterios de diferenciación específicos de marca y producto, para asociar sus discursos a la necesidad de unión, solidaridad y esperanza que exigía la explosión de la pandemia.

Esta investigación plantea un método para monitorizar la influencia del contexto social en la comunicación de los valores humanos. Medir iterativamente de qué modo son percibidos los mismos valores a través de los mismos mensajes, en distintas etapas de evolución de una situación crítica, abre una línea de investigación que puede aportar resultados muy fiables para determinar la interacción entre los mensajes y sus contextos. 


\section{Referencias bibliográficas}

ArCe Media-Auditsa (2020a). Impacto del Covid-19 / 1-31 de marzo: Ocupación por medios. Arce Media-Auditsa. Recuperado de <http://www.arcemedia.es/ informes/ArceMedia-ImpactoCovid19-1-31Marzo2020.pdf> [Fecha de consulta: $11 / 07 / 2020]$.

- (2020b). Impacto del Covid-19 / 1-30 de abril: Ocupación por medios. Arce Media-Auditsa. Recuperado de <http://www.arcemedia.es/informes/ArceMediaImpactoCovid19-1-30Abril2020.pdf> [Fecha de consulta: 11/07/2020].

BADAjOz, D. y Rodríguez-Bravo, A. (2018). «¿Cómo medir la eficacia comunicativa?: El modelo de los umbrales comunicativos». En: TEJERO, B.; BERNARD, O. y LECHUGA, C. (2018). Investigando en contenidos de vanguardia. Madrid: Gedisa, 29-43. Recuperado de <https://ddd.uab.cat/record/219271>.

BARlovento COMUNiCACIÓN (2020). Informe Consumo Internet vs. Televisión: Marzo 2020 (28 de abril). Madrid: Barlovento Comunicación. Recuperado de <https://www.barloventocomunicacion.es/audiencias-mensuales/informeconsumo-internet-vs-television-marzo-2020/> [Fecha de consulta: 11/7/2020].

BERISTAIN, J. J. (2020). «La verdadera naturaleza de las marcas: Marketing y Branding en tiempos de pandemia». Ehusfera. Recuperado de <http://www.ehu.eus/ehusfera/ enpresa-institutua/2020/05/04/la-verdadera-naturaleza-de-las-marcas-marketing-ybranding-en-tiempos-de-pandemia/> [Fecha de consulta: 12/07/2020].

BUSINESS INSIDER ESPAÑA (2020). Ranking de los medios de comunicación más utilizados por la población para informarse sobre el coronavirus en España a fecha de marzo de 2020. Axel Springer España. Recuperado de <https://www.businessinsider.es/ como-estan-viviendo-espanoles-cuarentena-coronavirus-605397/> [Fecha de consulta: 20/10/2020].

«¿Cómo pueden las marcas responder a la crisis del Coronavirus?». El Publicista (13 de marzo de 2020). Recuperado de <https://www.elpublicista.es/articulos/comopueden-marcas-responder-crisis-coronavirus $>$ [Fecha de consulta: 9/07/2020].

DELFinO, G. y MurATORI, M. (2011). "Análisis factorial confirmatorio de la escala de valores de Schwartz». 3er Congreso Internacional de Investigación. 15-17 de Noviembre-2011, 133-140. Recuperado de <http://www.memoria.fahce.unlp. edu.ar/trab_eventos/ev.1460/ev.1460.pdf>.

Giusta, M. D.; Hashimzade, N. y MYles, G. D. (2017). "Schooling and the Intergenerational Transmission of Values». Journal of Public Economic Theory, 19 (1), $1-17$. <https://doi.org/10.1111/jpet.12184>

GuZMÁN-OBANDO, J.; GONZÁlEZ, G.; RosA, J. L. de la, et al. (2016). «Una aproximación de la escala de valores a partir de los smart user». En: ZAVALA-DÍAZ, J. y Cruz-Chávez, M.A. AGECOMP2005, Memorias del 4to Congreso de Cómputo. México: UAEM, 96-109. ISBN(e) 968-878-250-5.

HERNÁNDEZ-OlmEDO, J. L. (2016). «El camino persuasivo de los valores en la propaganda televisiva». Comunicación y Sociedad, 27, 145-173. <https://doi.org/10.32870/cys.v0i27.2764>

InGLEHART, R. y BAKER, W. (2000). «Modernization, Cultural Change, and the Persistence of Traditional Values». American Sociological Review, 65 (1), 19-51. $<$ https://doi.org/10.2307/2657288>

IPSOS (2020). El consumidor post-Covid se centrará en el ahorro, estará más digitalizado $y$ priorizará la compra de productos frescos y saludables. IPSOS Iberia. Recuperado de 
$<$ https://www.ipsos.com/es-es/el-consumidor-post-covid-se-centrara-en-el-ahorroestara-mas-digitalizado-y-priorizara-la-compra-de> [Fecha de consulta: 20/4/2020].

KampS, B. S. y HofFmann, C. (2020). COVID Reference. $4 .^{\mathrm{a}}$ ed. Hamburgo: Steinhäuser Verlag. Recuperado de <https://covidreference.com/>.

KANT, I. (1786). Grundlegung des Metaphysik der Sitten. Riga: Hartkoch.

Konty, M. A. y ChORN DUnham, C. (1997). «Differences in value and attitude change over the life course». Sociological Spectrum, 17 (2), 177-197. $<$ https://doi.org/10.1080/02732173.1997.9982159>

Lage Fombuena, A. (2016). Modelos de deseo: Modelado de los rasgos visuales y evaluación de valores de los estereotipos mujer objeto de deseo en las revistas de moda. Universitat Autònoma de Barcelona. Tesis doctoral. Recuperado de <https://ddd. uab.cat/record/176038>.

«Las marcas congelarán su inversión publicitaria durante al menos 6 meses debido al Coronavirus». Reasonwhy (14 de mayo de 2020). Recuperado de <https://www. reasonwhy.es/actualidad/retencion-inversion-publicitaria-grandes-marcascoronavirus-2020> [Fecha de consulta: 23/05/2020].

Mas-ManChÓn, L.; RodrígueZ-Bravo, Á.; Montoya-Vilar, N. et al. (2015). «Valores percibidos en la publicidad de alimentos por jóvenes con y sin trastornos de la conducta alimentaria». Revista Salud Colectiva, 11, 423-444. $<$ https://doi.org/10.18294/sc.2015.729>

- (2016). "Values perception in food commercials with dietary strategies». Revista Prisma Social, número especial 1, 29-59. Recuperado de <http://revistaprismasocial. es/article/view/1313/1377>.

Montoya, N.; Rodríguez Bravo, Á. y Lopes, E. (2018). «Herramienta para la medición de valores corporativos en las organizaciones: ProtocoloEva ". $13^{\circ}$ Congreso Internacional de Investigación en Relaciones Públicas. Girona, 11-13 de abril de 2018. Recuperado de <https://ddd.uab.cat/record/196436>.

«Número de contagiados y fallecidos por coronavirus en Espańa y el mundo». La Vanguardia (23 de mayo de 2020). Recuperado de <https:/www.lavanguardia. com/vida/20200323/4850693664/numeros-contagiados-muertos-coronavirusspana-mundo.html> [Fecha de consulta: 23/05/2020].

RODRIGO-MARTíN, I. y RODRIGO-MARTÍN, L. (2014). «La causa social en la creatividad publicitaria». Pensar la Publicidad: Revista Internacional de Investigaciones Publicitarias, 7 (2), 253-274. <https://doi.org/10.5209/rev_pepu.2013.v7.n2.46177>

RODRÍGUEZ-BraVO, A. et al. (2013). «Medición y evaluación de valores en contenidos audiovisuales desde un abordaje interdisciplinar». Prisma Social, 11, 158-204. Recuperado de <http://www.redalyc.org/articulo.oa?id=353744535006>.

- (2017). ProtocoloEva: Desarrollo y validación de una herramienta cientifica para la medición y evaluación de valores en contenidos audiovisuales. Bellaterra (Barcelona): Laicom, 2017 SGR115. Recuperado de <https://ddd.uab.cat/record/199488?ln= ca\#.XH7J-WaHsfM>.

- (2020). «Valores corporativos de los principales bancos españoles». Revista Prisma Social, 28, 44-73. Recuperado de <https://revistaprismasocial.es/article/ view/3329/4080>.

ROKEACH, M. (1973). The nature of human values. 1. a ed. Nueva York: Free Press.

SALIM SAJI, B. (2015). "Selection of Tourism Destination as a Representation of Human Values». Business Perspectives and Research, 3 (2), 95-108. <https://doi.org/10.1177/2278533715578554> 
SCHWARTZ, S. H. (1996). "Value priorities and behavior: Applying a theory of integrated values systems». En: Seligman, C.; Olson, J. M. y ZanNA, M. P. (eds.). The psychology of values: The Ontario symposium, 8, 1-24. Mahwah, NJ: Erlbaum.

SEPÚlVEDA RíOS, I. J. (2017). Los estereotipos de la mujer mexicana en los mensajes gráficos electorales: Análisis de percepción de valores del elector. Universitat Autònoma de Barcelona. Tesis doctoral. Recuperado de <https://www.tdx.cat/ handle/10803/455149>.

SHELER, M. (1916). Der Formalismus in der Ethik und die materiale Wertethik. Halle a. d. S.: Verlag von Max Niemeyer.

Sortheix, F. M.; PArker, P. D. y LeChner, C. M. et al. (2019). "Changes in Young Europeans' Values During the Global Financial Crisis». Social Psychological and Personality Science, 10 (1), 15-25. <https://doi.org/10.1177/1948550617732610>

Torralba Rosselló, F. (2010). «Valores emergentes en tiempos de crisis». Corintios XIII: Revista de Teología y Pastoral de la Caridad, 134, 19-39.

VEIRA, J. (coord.) (2010). La evolución de los valores sociales en Galicia. Oleiros (La Coruña): NetBiblo. 446 p.

WALLS, J. L. (2018). Identifying human values reflected in 'Digitoral' marketing campaigns. Fielding Graduate University - ProQuest. Recuperado de <https://www. proquest.com/docview/2059792542?pq-origsite=gscholar\&fromopenview=true $>$.

YAGÜE-López, L.; SÁNCHEZ-RodríGueZ, A. I.; Miguel-Negredo, A. et al. (2013). «Sexo y cohorte como fuentes de diferenciación en valores en la sociedad postmoderna». International Journal of Psychology and Psychological Therapy, 13 (2), 243-253. Recuperado de <https://pdfs.semanticscholar.org/294f/3c24259d1 d7f4b384505438a453e2df0abb9.pdf>

\section{Anexo 1}

Querido/querida

En nuestro grupo de investigación estamos haciendo un estudio sobre cómo evoluciona la comunicación de valores durante la pandemia ¿Puedes echarnos una mano viendo unos anuncios de TV y contestando a un TEST?

Aquí tienes las instrucciones y el enlace al TEST:

1. Clica el enlace que verás al final del mensaje.

2. Regístrate en el cuadro inferior de la primera pantalla, donde pone: "Usuarios nuevos».

3. Mira el primer vídeo que explica como responder al TEST.

4. Clica el botón "Iniciar».

5. Evalúa los 5 anuncios del TEST (solo tienes que seguir las instrucciones).

\section{Acceso para responder al TEST:}

<https://protocoloeva.uab.cat/test/login/identerprise/87? identerprise $=87 \& \mathrm{id}$ $=1 \& \mathrm{key}=341246 \mathrm{~b} 89 \mathrm{~cd} 0 \mathrm{a} 4 \mathrm{~d} 91 \mathrm{e} 623650669 \mathrm{c} 572 \mathrm{c}>$ 


\section{Anexo 2. Tablas generadas por el aplicativo ProtocoloEva}

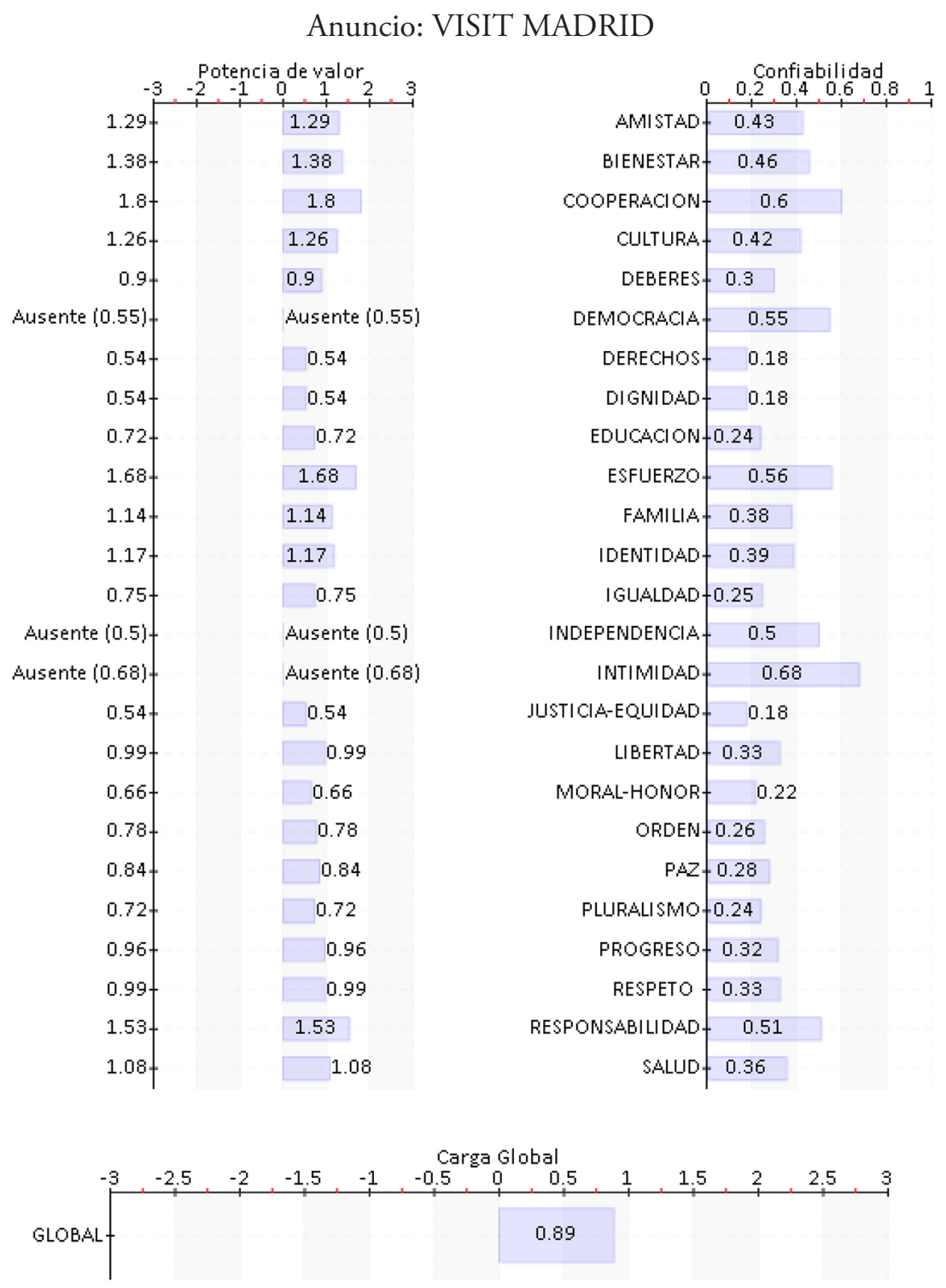




\section{Anuncio: FLORETTE}
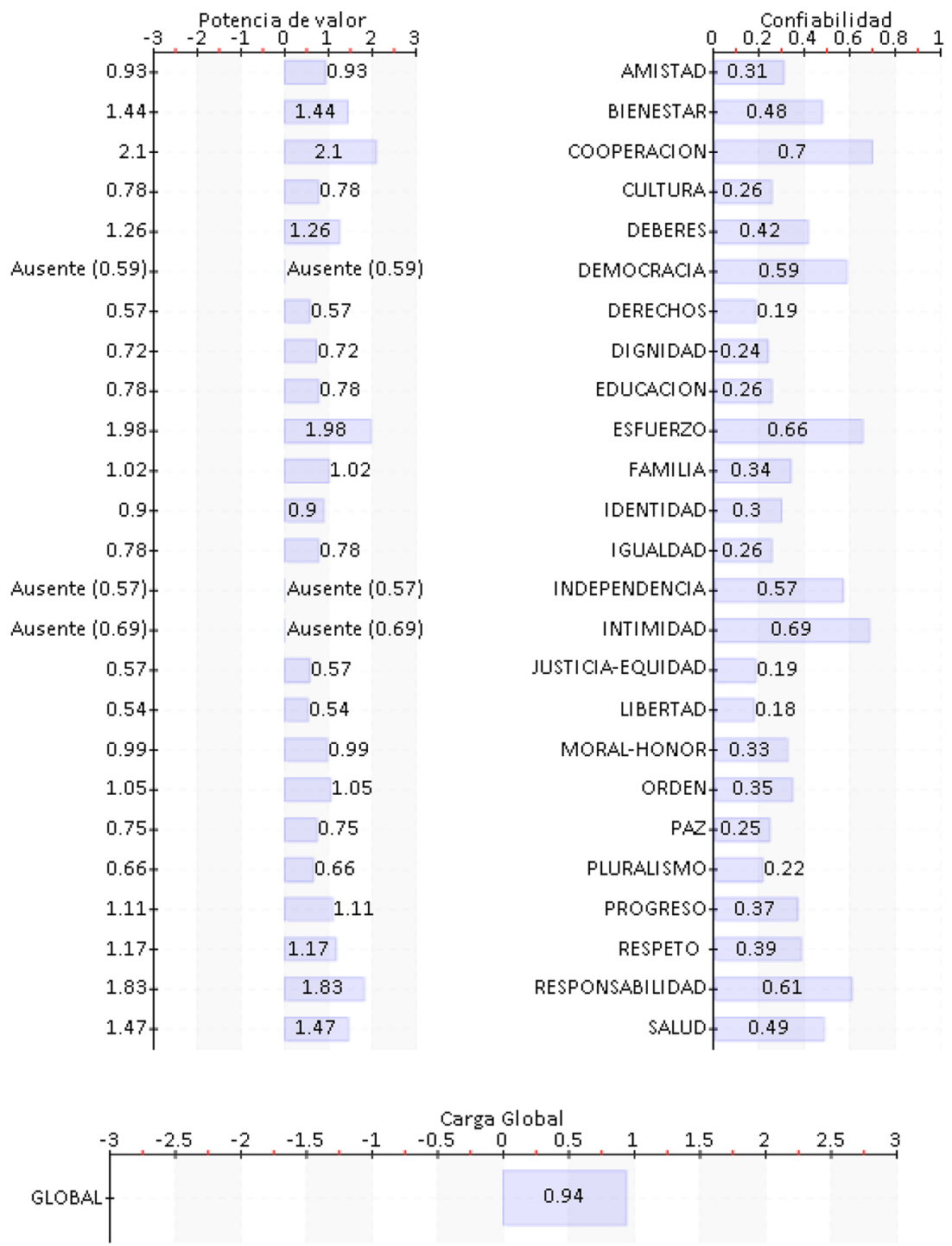
Anuncio: FUNDACIÓN BBK
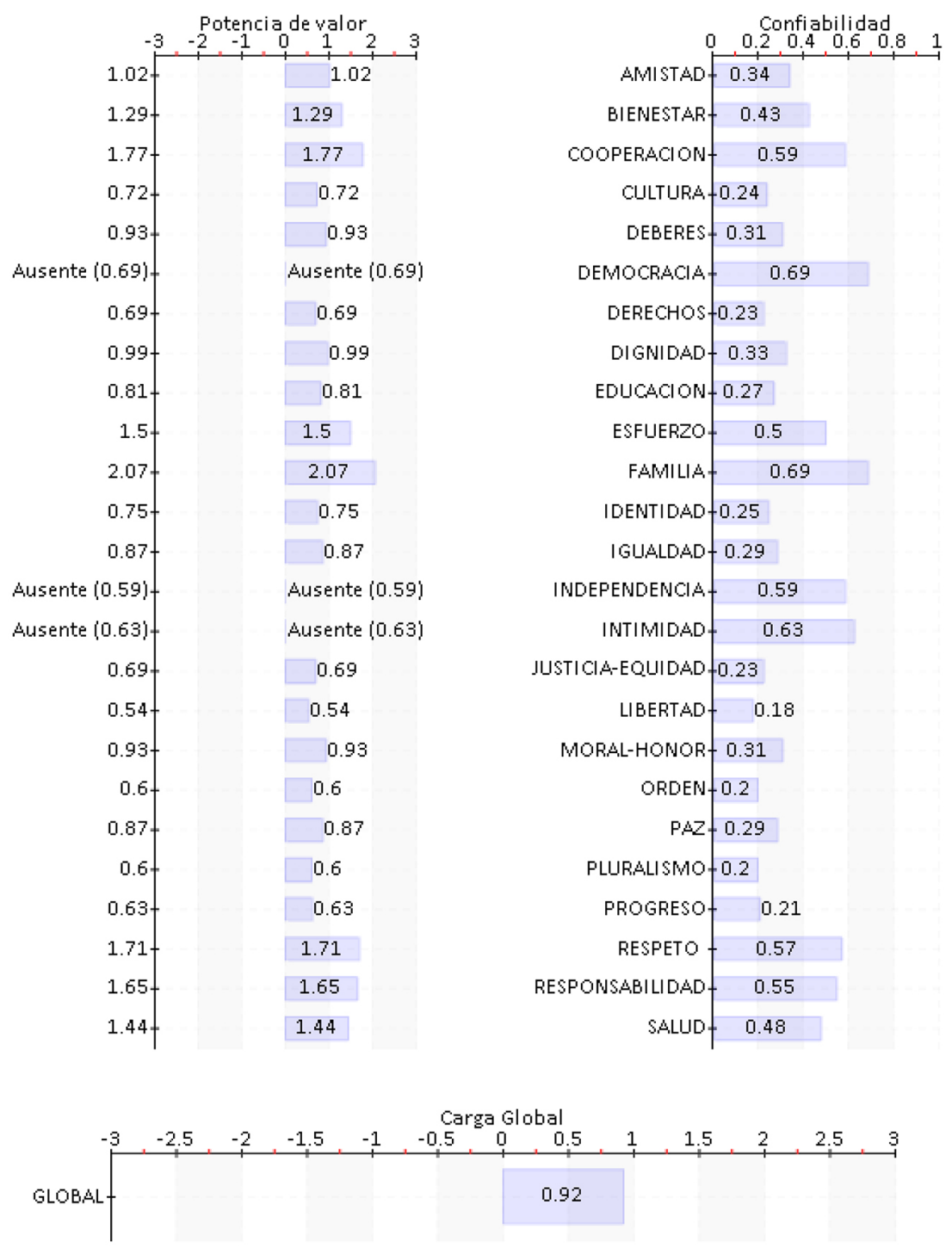


\section{Anuncio: VOLKSWAGEN}
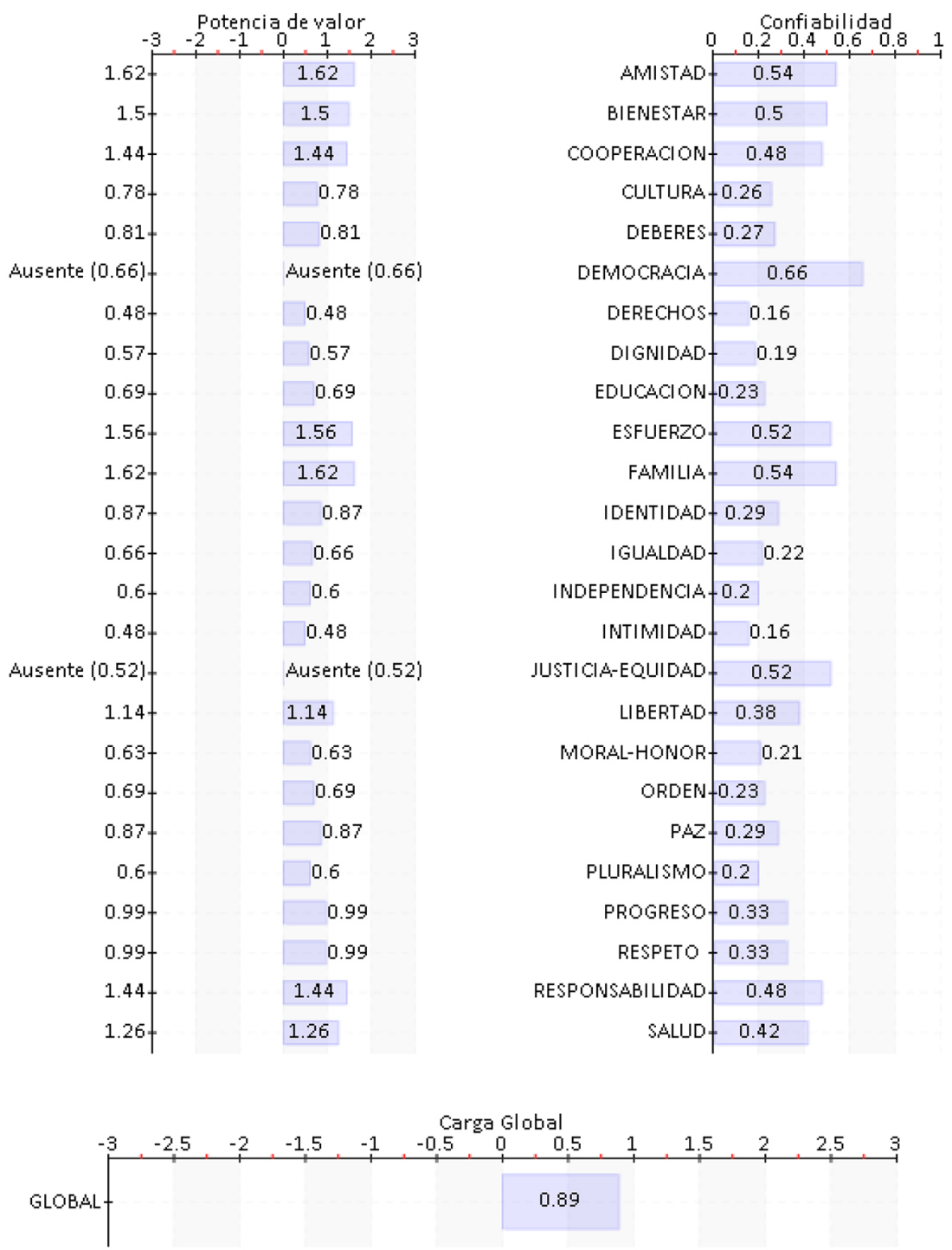